\title{
CORPO, GÊNERO E SEXUALIDADE NA CIBERCULTURA: MODOS DE CONHECER, PRÁTICAS DE SOCIABILIDADE E REDES EDUCATIVAS
}

\author{
BODY, GENDER AND SEXUALITY IN CYBERCULTURE: \\ WAYS OF KNOWING, SOCIABILITY PRACTICES AND EDUCATIONAL NETWORKS \\ CUERPO, GÉNERO Y SEXUALIDAD EN CIBERCULTURA: \\ FORMAS DE CONOCIMIENTO, PRÁCTICAS DE SOCIABILIDAD Y REDES EDUUCATIVAS. \\ Fernando Pocahy \\ Felipe da Silva Ponte de Carvalho ${ }^{2}$ \\ Dilton Ribeiro Couto Junior ${ }^{3}$
}

As tecnologias digitais conectadas à internet vêm possibilitando novos modos de conhecer, novas práticas de sociabilidade e redes educativas, dando sentido e forma à cibercultura (LÉVY; LEMOS, 2010). Uma vez que a infraestrutura técnica das interfaces digitais hoje permite que as/os usuárias/ os permaneçam interconectadas/os produzindo colaborativamente novos saberes, deixamos de ocupar o (suposto) lugar de meras/os consumidoras/es de informações e passamos a produtoras/es ativas/es de conteúdos a serem compartilhados/produzidos para a Web (LEMOS, 2002; PRIMO, 2000). Em tempos de cibercultura, precisamos aproveitar o espaço da rede para trocar e aprender juntas/ os por meio da partilha de autorias (SANTOS; CARVALHO, 2018), reconhecendo desde já que essas trocas trazem implicações importantes para a pesquisa em educação.

Estudiosas/os dos processos sociais e das práticas culturais (SANTOS, 2011; CASTELLS, 2013; RECUERO, 2012) vêm apontando que o cotidiano é cada vez mais mediado pelo digital em rede, possibilitando que novos espaços-tempos sejam experimentados com outras/os usuárias/os geograficamente dispersas/os. Pesquisar no contexto dessas práticas ciberculturais, mirando nosso olhar sobre o que vem sendo produzido-compartilhando na/em rede, exige movimentos de reflexão ético-política constantes sobre as novas tecnologias de subjetivação que vêm sendo constituídas na interação entre usuárias/os nas redes sociais online.

Diante dos processos comunicacionais ciberculturais não podemos deixar de mencionar a intensa produção de práticas que envolvem a produção de marcadores de diferença, notadamente gênero e sexualidade, entre outras intersecções (raça, geração, classe social etc), produzindo novos sentidos e significações para o corpo. No jogo da produção da diferença os embates sociais se estabelecem em oposição às normas (marcadas no jogo intenso da diferença). 0 que aponta para dissidências inclusive no interior das zonas de exclusão (como uma sorte de dentro-fora), uma vez que as relações de saber-poder em torno dessa produção/ marcação são difusas e incessantes - revelando a agonística de todas as relações sociais e porque dificilmente estaremos totalmente livres de uma nova relação que deseja a norma e o assujeitamento de outrem. 
Gênero e sexualidade cada vez mais têm nos possibilitado tecer outros entendimentos sobre nossos corpos, desejos, prazeres e formas de produzir conhecimento sobre o/com o mundo e, efetivamente, sobre nós mesmas/os. Consideramos assim que a produção de conhecimento e de outras maneiras de aprender-ensinar encontram-se agenciadas em múltiplas e complexas redes educativas, para além dos espaços-tempos institucionais, oferecendo-nos a possibilidade de pensarmos em espaços outros e modos de subjetivação insurgentes na/com a cibercultura. Concordamos que precisamos ocupar o espaço das redes sociais online, buscando "cavar cada vez mais brechas de (re-)existência em parceria com outras/ os internautas geograficamente dispersas/os, fazendo também da internet nosso dispositivo político em prol do alargamento de nossas margens de liberdade" (COUTO JUNIOR; BRITO; POCAHY; AMARO, 2019, p. 1225). Em tempos de constantes ataques aos grupos minoritários, não duvidamos da potência da rede como mais um importante espaço na promoção de outras possibilidades de (re-)existências.

Este dossiê aposta em um olhar interdisciplinar sobre gênero, sexualidade em posições dissidentes articulados aos espaços-tempos da cibercultura como uma das arenas mais evidentes da/na produção de modos de vida contemporâneos. Como profissionais do campo da Educação, apostamos no potencial deste dossiê para ampliar nosso olhar acerca da importância de se discutir gênero e sexualidade na escola (e para além dela), principalmente em tempos de crescente ódio às chamadas minorias sexuais, étnico-raciais e de gênero. Acreditamos na mobilização dos diferentes segmentos da sociedade que vêm agenciando resistências, mobilizações e solidariedade articuladoras de insurgências epistemológicas, expressas em aprendizagens-ensinanças em práticas cotidianas de cidadania-ética. Percebemos através dos trabalhos que integram este dossiê a emergência de novas experimentações de mundo, acontecimentos cotidianos que ampliam o conhecimento socialmente (des-re)construído, oferecendo formas-outras de habitar o cotidiano. Na direção de vida não-fascista (FOUCAULT, 1993) é que nos movimentamos no encontro com as tecnologias digitais em rede e com os seus praticantes.

O dossiê, constituído de dezenove artigos e uma entrevista, assume os desafios da expansão desses novos territórios e paisagens existenciais em disputa, acompanhado a emergência de novas dinâmicas interativas e comunicacionais do nosso tempo. Abarcando temas e concepções teórico-metodológicas distintos, os textos que integram o dossiê revelam a riqueza do campo de estudos de gênero e sexualidade como objeto de pesquisa. Corpos, gêneros, sexualidades, transexualidade, heteronormatividade, performatividade, infâncias, masculinidades, aplicativos de namoro/"pegação", censura, resistência, diferença, violência, redes sociais e pornocultura, apenas para citar alguns exemplos, fazem parte da trama analítica de trabalhos desenvolvidos por pesquisadoras/es de diversas regiões do país implicadas/os com a análise de discussões do tempo presente.

0 primeiro artigo que inaugura o dossiê, intitulado "Infâncias nas dobras da norma: entre narrativas e experiências de gêneros no ciberespaço", é de autoria de Raquel Gonçalves Salgado e Leonardo Lemos de Souza. 0 texto analisa narrativas de infância no ciberespaço, mais especificamente as narrativas presentes nas coletâneas online Chonguitas: masculinidades de niñas e Mariconcitos: feminidades de niños, placeres de infancia. Com isso, destaca-se a presença de corpos dissidentes de crianças como um ideário construído a partir da relação infância-inocência.

O segundo trabalho, assinado por Larissa Pelúcio, é intitulado "Um match com os conservado- 
rismos: masculinidades desafiadas nas relações heterossexuais por meios digitais". 0 estudo, de natureza etnográfica, investigou como homens (entre 29 e 60 anos) usuários de aplicativos móveis voltados para relacionamentos amorosos/sexuais (Adote um Cara, Happn e Tinder) estão lidando com seus afetos diante da inflexão feminista vivida pelo país nas últimas duas décadas. A partir da interação com eles, a autora destaca que muitos desses sujeitos têm tido dificuldades em lidar com a agenda feminista e, embora o avanço dessa agenda esteja provocando reflexões em torno das questões de gênero e sexualidade, esses homens consideram-se conscientes de que se orientam pelos alicerces machistas na constituição de suas masculinidades.

Em seguida, “Odiados pela nação: como ensinamos e aprendemos a odiar a diferença?”, texto de Felipe da Silva Ponte de Carvalho e Fernando Pocahy, analisa o episódio "Odiados pela Nação" da série Black Mirror. Na pesquisa-cartográfica, os autores discutem a forma como aprendemos-ensinamos a odiar a/o outro/a a partir de reflexões sobre acontecimentos que compõem a ambiência de guerra de ódio à diferença em nosso tempo.

O quarto texto do dossiê, escrito por Telma Brito Rocha e Cleyton Williams G. S. Brandão, é intitulado "Violência Contra Mulheres nas Redes Sociais: o caso Elaine Perez Caparró". O trabalho buscou promover reflexões em torno dos discursos de ódio direcionados às mulheres no Facebook, apontando para um quadro preocupante envolvendo o machismo, culpabilização da vítima e difamação, apenas para citar alguns exemplos. Frente a isso, os autores apontam para a importância de se colocar em prática uma educação transformadora que contribua com a formação de pessoas mais críticas e reflexivas em vistas de superar esse quadro de violência de gênero no Brasil.

Posteriormente, o trabalho de Luiz Felipe Zago e Thanise Guerini Atolini, intitulado "Pedagogias da sexualidade na pornocultura: notas sobre as milfs", investiga as pedagogias da sexualidade de vídeos do site estadunidense YouPorn, com ênfase no gênero pornográfico milf (mother's l'd like to fuck, em inglês). 0 autor e a autora propuseram-se a analisar a personagem pornográfica milfdos vídeos analisados e, ademais, também dedicaram seus esforços reflexivos em discutir a pornocultura da internet.

O sexto artigo do dossiê desenvolvido por Eder Fernandes Monica e Ramon Silva Costa é intitulado "Privacidade, liberdade sexual e sigilo: sentidos de liberdade no aplicativo Grindr". O texto investiga os sentidos de privacidade e liberdade sexual de usuários do Grindrque, por meio do aplicativo, buscam contatos sexuais sigilosos com outros homens. 0 estudo indica que existe diferentes formas com as quais as dinâmicas do digital em rede agem na constituição das masculinidades, ao mesmo tempo em que considera o aplicativo um espaço privilegiado para a experiência sexual de homens que se encontram imersos em contextos que reiteram a naturalização da heterossexualidade.

“Do dejeto ao desejo: arquitetura de banheiros como dispositivo de controle da sexualidade" é o próximo texto do dossiê, escrito por Gleiton Matheus Bonfante e Filipe Ungaro Marino. 0 artigo discute a arquitetura dos banheiros públicos do Rio de Janeiro e desenvolve reflexões acerca dos dispositivos de controle de sexualidade. Considerando as convenções de gênero historicamente atribuídas ao espaço do banheiro público, visto como um local de vulnerabilidade fisiológica e privacidade, os autores reconhecem que a prática da pegação em banheiros é uma forma subversiva e de resistência à heteronormatividade e à perspectiva binária de compreensão dos gêneros. 
O oitavo trabalho do dossiê, “O fascínio e a espetacularização como pedagogias do corpo no World of Warcraft", de autoria de Julio Cesar Gomes Santos e Edvaldo Souza Couto, traz resultados de uma pesquisa que investigou construções de pedagogias corporais a partir de uma análise sobre os processos de fascínio e espetacularização do corpo nas representações dos personagens do jogo eletrônico World of Warcraft. No jogo, a espetacularização do corpo evidenciou a necessidade dos sujeitos de acessarem experiências diferenciadas que permitem a produção de novos aprendizados na cultura da visibilidade.

O texto de Sônia Beatriz dos Santos e Isadora Faria Lacerda, intitulado "Sexualidade da mulher e tabu no ambiente escolar: uma revisão da literatura”, apresenta uma revisão bibliográfica sobre a sexualidade da mulher vivenciada no ambiente escolar mediante a análise de teses e dissertações do banco da CAPES e da base Scielo de periódicos. A produção acadêmica analisada no nono texto do dossiê observou modos como a sexualidade da mulher ainda é percebida como tabu no espaço escolar, sendo também demasiadamente invisibilizada no meio acadêmico. Para a melhora desse cenário, as autoras argumentam que ainda temos um longo caminho pela frente, sendo necessário também mudanças nas instituições educacionais.

“A noção de gênero nos livros didáticos de Sociologia para o ensino médio”, escrito por Renato Kendy Hidaka e Gabriela Sebba Abdo se propõe a analisar a forma como o marcador social gênero é tratado nos livros didáticos de Sociologia para o ensino médio aprovados pelo Programa Nacional do Livro Didático (PNLD) (triênio 2015-2017). Para isso, realizou-se uma análise que girou em torno de questões voltadas principalmente para a presença (e ausência) da noção de gênero no conteúdo desses livros e como esse marcador é explorado teoricamente no material.

Paulo Melgaço da Silva Júnior e Leandro Teofilo de Brito, no artigo "Entre nudes, acontecimentos e performatizações: normatizações/deslocamentos de gênero e sexualidade no cotidiano escolar", abordam o compartilhamento de nudes por dispositivos móveis entre estudantes de uma escola da rede municipal de Duque de Caxias/Rio de Janeiro. Esse acontecimento agitou o cotidiano da instituição de ensino e ajudou a promover dentro da escola a realização de um projeto sobre questões de gênero e sexualidade nas práticas pedagógicas.

No artigo "Políticas de narratividade e performances gênero na escola: cartografias em aberto”, Lucemberg Rosa de Oliveira, Ana Lúcia Gomes da Silva e Juliana Cristina Salvadori discutem como as categorias de gênero, práticas pedagógicas e formação docente estão presentes no cotidiano escolar e de que maneira atravessam as práticas das/os professoras/es dos/a professores/a. Como resultado desse artigo discutem como muitas/os professoras/es muitos/a professores/a ainda se sentem reféns de práticas pedagógicas incoerentes com as demandas dos sujeitos da contemporaneidade presentes na escola.

Em "A conversa online como procedimento metodológico na pesquisa com masculinidades dissidentes na cibercultura: notas teórico-metodológicas" Ruann Moutinho Ruani, Dilton Ribeiro Couto Junior e Ivan Amaro abordam como as normas regulatórias de gênero e sexo atuam na formação das masculinidades de pessoas autoproclamadas gays usuárias de aplicativos de pegação/ namoro. Os autores apostam no reconhecimento da conversa online como um procedimento metodológico alinhado com uma dimensão dialógica e de alteridade que visa a horizontalidade das vozes na interação com homens gays que performatizam masculinidades dissidentes. 
No décimo quarto artigo que compõe o dossiê, “Dissidências sexuais e de gênero no humor: estigma e resistência entre a TV e a Internet", Rafael Silva de Carvalho analisa os enunciados, as relações de poder e as produções de subjetividades a partir de dois vídeos humorísticos em torno das dissidências sexuais e de gênero. Os vídeos escolhidos para a pesquisa são esquetes de humor de personagens que marcaram época na televisão brasileira entre as décadas de 1980 e 1990. Nos resultados da pesquisa o autor tensiona entre discute a produção de estigma e possibilidades de resistência através do humor na Televisão e internet. Internet

“Educação, Corpos e suas Resistências na Cultura Digital: Análise de uma narrativa audiovisual sobre gênero", autoria de Rafaela Ferreira dos Santos, Rosilaine Wardenski e Taís Rabetti Giannella problematiza uma experimentação com alunxs do ensino fundamental, a partir dos os significados inscritos nos corpos, que levam a sua produção, ou seja, a sua generificação. Como resultada da pesquisa, as autoras destacam: (1) a crítica das alunas às práticas de bullying contra os sujeitos, que se afastam de modelos hegemônicos de feminilidade; e (2) o quanto as representações dos corpos presentes nos materiais didáticos, que contribuem com a naturalização das diferenças ao reforçar o pensamento binário e a normatização, por meio de uma performance, em que se evidencia que narrar é resistir.

Michelle Viana Trancoso, Tania Lucía Maddalena e Edméa Santos assinm "Cartografía de una red de saberes: el cotidiano de un espacio social femenino en Facebook". Nesse texto cartografam grupos feministas no Facebook durante a campanha eleitoral de Jair Bolsonaro de em 2018 no Brasil, buscando compreender as construções dos espaços sociais femininos como redes educativas e como estas promovem desde a literacia digital até as discussões e problematizações conceituais de interseccionalidade e machismo.

O décimo sétimo artigo, escrito por Luciana Velloso, intitula-se “Ler é um ato político: multiletramentos em contexto de censura literária”. Nele a autora analisa o papel dos memes como potência crítica de oposição às ações do atual prefeito da cidade do Rio de Janeiro durante a Bienal do Livro de 2019 e aos defensores de movimentos conservadores em relação à leitura e ao contexto social mais amplo.

No artigo "\#Diferença sexual - pensando e discutindo na/da sociedade do compartilhamento", Cristiano Sant'Anna de Medeiros analisa as imagens compartilhadas por estudantes do terceiro ano do Ensino Médio, do Colégio Estadual Abdias Nascimento, em Nova Iguaçu, Baixada Fluminense/RJ. 0 autor destaca que tanto a imagem quanto as narrativas fornecem pistas para pensar as ideias de diferenças que são criadas e circulam nas múltiplas redes educativas.

Em “Do gênero aos papéis sociais: a construção da identidade da pessoa transexual” Larissa Porto, Mariana Leonesy da S. Barreto e Maria Virgínia Machado Dazzani discutiram, através de uma revisão bibliográfica, os papéis de gênero na constituição da identidade da pessoa transexual. As autoras apontam para a necessidade de políticas públicas e de novos estudos que analisem a trajetória das pessoas que optam pela cirurgia de transgenitalização.

O último trabalho que compõe o dossiê é uma entrevista realizada por Sara Wagner Pimenta Gonçalves Junior à Faye Venetia Harrison. Autora de "Outsider Within: Retrabalhando a Antropologia na Era Global”. Faye Harrison é antropóloga sociocultural que vem discutindo uma antropologia 
descolonizante. A autora analisa modos de subjetivação das identidades e o rompimento com os processos reprodutores de conhecimento que seguem produzindo colonialidade. Sara Gonçalves Junior é estudante de Mestrado no Programa de Pós-Graduação em Educação da Universidade do Estado do Rio de Janeiro (ProPEd/UERJ), professora alfabetizadora, latina e travesti. Juntas dialogam sobre pesquisa, educação e redes de (in)formação.

Em tempos de constantes ataques às chamadas minorias sociais e dos profundos cortes nas pesquisas que vêm sendo desenvolvidas nas universidades brasileiras, consideramos este dossiê um entre tantos outros gestos de resistência que se movimentam nas redes acadêmicas e científicas pelo país. Como afirma Pocahy (2018, p.13-14): “Vem desses desafios a urgência de pensar o que estamos fazendo de nós mesmXs, como movimento de fazer fugir e escapar, como dissidência e como uma sorte de des(a)fiamento político-científico-epistemológico engendrado na pluralidade cultural e nas tramas das infinitas e complexas redes de desigualdade que nos interpelam nos cotidianos de nossas vidas".

Ousamos (re-)existir e produzir/compartilhar em/na rede conhecimento de qualidade, nos munindo de um arsenal teórico que possa compor nossas lutas cotidianas em defesa da universidade pública, gratuita, laica e de qualidade. Frente a isso, não há dúvida de que "precisaremos fortalecer nossas lutas na constituição de mobilizações políticas capazes de interligar os esforços coletivos em prol de alianças mais potentes que nos confiram a capacidade de ampliar nossas margens de liberdade" (BRITO; COUTO JUNIOR, 2019, p. 300). Acreditamos no potencial das redes digitais para uma mobilização mais ampla que nos confira maior participação nos processos comunicacionais em/na rede, ampliando nosso fazer político em vistas de assegurar que nossa luta cotidiana no Brasil se dê por meio de vias democráticas e populares.

\section{Desejamos a todxs ótima leitura!}

\section{REFERÊNCIAS}

BRITO, Leandro Teofilo de; COUTO JUNIOR, Dilton Ribeiro. Performatizações dissidentes na escola: masculinidades precárias em discussão. Periódicus, Salvador, v.1, n. 11, p. 284-302, maio/out. 2019. Disponível em: <https://bit.ly/208Pdn6>. Acesso em: 29 jan. 2020.

CASTELLS, Manuel. Redes de indignação e esperança: movimentos sociais na era da internet. Tradução de Carlos Alberto Medeiros. Rio de Janeiro: Zahar, 2013.

COUTO JUNIOR, Dilton Ribeiro; BRITO, Leandro Teofilo de; POCAHY, Fernando; AMARO, Ivan. Jovens em estado de alerta no Facebook: diálogos tecidos em/na rede como estratégia de (re-)existência à regulação das vidas precarizadas. Práxis Educativa, Ponta Grossa, v. 14, n. 3, p. 1210-1229, set./ dez. 2019. Disponível em: <https://bit.ly/2oqpqfW>. Acesso em: 2 out. 2019. FOUCAULT, Michael. O Ante-édipo: uma introdução à vida não fascista. Cadernos de Subjetividade / Núcleo de Estudos e Pesquisas da Subjetividade do Programa de Estudos Pós-Graduados em Psicologia Clínica da PUC-S, São Paulo, v. 1, n. 1, p. 197-200, 1993. 
LEMOS, André. Aspectos da cibercultura: vida social nas redes telemáticas. In: PRADO, José Luiz Aidar (Org.). Crítica das práticas midiáticas: da sociedade de massa às ciberculturas. São Paulo: Hacker, 2002, p. 112-129.

LEMOS, André; LÉVY, Pierre (Org). 0 futuro da internet: em direção a uma democracia planetária. São Paulo: Paulus, 2010.

POCAHY, Fernando. O clamor da diferença letal: educar em estado de exceção. Revista Ñanduty, v. 6, p. 9-22, 2018.

PRIMO, Alex. Interação mútua e interação reativa: uma proposta de estudo. Revista Famecos, Porto Alegre, n. 12, p. 81-92, jun. 2000.

RECUERO, Raquel. A conversação em rede: comunicação mediada pelo computador e redes sociais na internet. Porto Alegre: Sulina, 2012.

SANTOS, Edméa. A cibercultura e a educação em tempos de mobilidade e redes sociais: conversando com os cotidianos. In: FONTOURA, Helena Amaral; SILVA, Marco (Orgs.). Práticas pedagógicas, linguagem e mídias: desafios à Pós-graduação em Educação em suas múltiplas dimensões. Rio de Janeiro: ANPEd Nacional, 2011, p. 75-98.

SANTOS, Edméa; CARVALHO, Felipe da Silva Ponte de. Autorias partilhadas na interface cidaderedes digitais. Interfaces Científicas - Educação, Aracaju, v. 6, n. 3, p. 29-40, jun. 2018. Disponível em: <https://bit.ly/2MQHAOF>. Acesso em: 20 jul. 2018.

1 Afiliação institucional: Universidade do Estado do Rio de Janeiro - UERJ, Faculdade de Educação (EDU) - Programa de Pós-Graduação em Educação - ProPEd/ Universidad Complutense de Madrid - UCM. 0 pesquisador conta auxílio CAPES Print UERJ, CNPq-Edital Universal e Jovem Cientista do Nosso Estado JCNE-FAPERJ E-mail: fernando.pocahy@gmail.com ORCID: https://orcid.org/0000-0002-7884-4647 Link Lattes: http://lattes.cnpq.br/0341333007755425

2 Afiliação institucional: Universidade do Estado do Rio de Janeiro - UERJ, Faculdade de Educação (EDU) - Programa de Pós-Graduação em Educação - ProPEd/ Universidad Complutense de Madrid - UCM. O pesquisador conta com auxílio do Programa de Estágio de Doutorandos no Exterior (Doutorado Sanduíche) FAPERJ. E-mail: felipesilvaponte@gmail.com ORCID: https://orcid.org/0000-0001-7398-6171 Link Lattes: http://lattes.cnpq.br/8539464540238508

3 Afiliação institucional: Universidade do Estado do Rio de Janeiro - UERJ/ FEBEF, Faculdade de Educação da Baixada Fluminense - PPGECC - Programa de Pós-Graduação em Educação, Cultura e Comunicação. 0 pesquisador conta com auxílio Programa Nacional de Pós-Doutorado - PNPD/CAPES. E-mail: junnior_2003@yahoo.com.br ORCID: https://orcid.org/00000002-5221-7135 Link Lattes: http://lattes.cnpq.br/3583771162535417 
